University of Wollongong

Research Online

Faculty of Engineering and Information

Faculty of Engineering and Information

Sciences - Papers: Part A

Sciences

$1-1-2014$

\title{
Vacancy-type defects study on ultra-fine grained aluminium processed by severe plastic deformation
}

Li-jun Su

University of Wollongong, lijun@uow.edu.au

C Lu

University of Wollongong

Guanyu Deng

University of Wollongong, gdeng@uow.edu.au

A Kiet Tieu

University of Wollongong, ktieu@uow.edu.au

L C. Zhang

University of Western Australia, Edith Cowan University, University of Wollongong, laichang@uow.edu.au

See next page for additional authors

Follow this and additional works at: https://ro.uow.edu.au/eispapers

Part of the Engineering Commons, and the Science and Technology Studies Commons

Research Online is the open access institutional repository for the University of Wollongong. For further information contact the UOW Library: research-pubs@uow.edu.au 


\title{
Vacancy-type defects study on ultra-fine grained aluminium processed by severe plastic deformation
}

\author{
Abstract \\ Vacancy-type defects play an important role in the metal materials deformed by severe plastic \\ deformation (SPD). The present work use positron annihilation lifetime spectroscopy (PALS) to test the \\ vacancy-type defects in aluminium alloys processed by equal channel angular pressing (ECAP) and \\ accumulative roll bonding (ARB). ECAP at room temperature and cryogenic temperature was conducted \\ to AA1050 and ARB with $200 \mathrm{C}$ preheating was conducted to AA1050 and AA6061 to produce laminated \\ AA1050 sheets, AA6061 sheets and AA1050/AA6061 composites. High fraction of vacancy-type defects \\ were detected in all the deformed samples. Vacancies associated with dislocations and bulk mono- \\ vacancies have been identified in RT-ECAP deformed samples. Three types of vacancy-type defects, \\ vacancies associated with dislocations, bulk mono-vacancies and bulk di-vacancies, have been identified \\ in the CT-ECAP processed samples. The ARB process is more efficient in grain refinement and \\ strengthening. However, the accumulation of vacancy-type defects in ARB deformation seems less \\ efficient. Vacancies associated with dislocations are the major vacancy-type defects for ARB processed \\ AA1050 sheets but there exist some bulk mono-vacancies. However, most of the vacancy-type defects in \\ the ARB processed AA6061 are vacancies associated with dislocations. A very small fraction of bulk \\ mono-vacancies can be extracted but it is so small that it can be neglected. The lifetimes of ARB \\ processed AA1050/AA6061 composites are generally in between the values of AA1050 sheets and \\ AA6061 sheets. Voids were not detected in neither of the samples.
}

\section{Keywords}

grained, aluminium, processed, severe, plastic, deformation, defects, type, study, vacancy, ultra, fine

Disciplines

Engineering | Science and Technology Studies

\section{Publication Details}

Su, L. H., Lu, C., Deng, G. Y., Tieu, K., Zhang, L. C., Guagliardo, P., Samarin, S. \& Williams, J. F. (2014). Vacancy-type defects study on ultra-fine grained aluminium processed by severe plastic deformation. Science of Advanced Materials, 6 (7), 1338-1345.

\section{Authors}

Li-jun Su, C Lu, Guanyu Deng, A Kiet Tieu, L C. Zhang, P Guagliardo, S N. Samarin, and J F. Williams 


\title{
Vacancy-Type Defects Study on Ultra-Fine Grained Aluminium Processed by Severe Plastic Deformation
}

\author{
L. H. Su${ }^{1}$, C. Lu $^{1, *}$, G. Y. Deng ${ }^{1,2}$, K. Tieu ${ }^{1}$, L. C. Zhang ${ }^{3}$, \\ P. Guagliardo 4 , S. N. Samarin ${ }^{4}$, and J. F. Williams ${ }^{4}$ \\ ${ }^{1}$ School of Mechanical, Materials and Mechatronic Engineering, University of Wollongong, Australia \\ ${ }^{2}$ State Key Lab of Rolling and Automation, Northeastern University, Shenyang, China \\ ${ }^{3}$ School of Engineering, Edith Cowan University, Australia \\ ${ }^{4}$ ARC Centre of Excellence for Antimatter-Matter Studies, School of Physics, The University of Western Australia, \\ Australia
}

\begin{abstract}
Vacancy-type defects play an important role in the metal materials deformed by severe plastic deformation (SPD). The present work use positron annihilation lifetime spectroscopy (PALS) to test the vacancy-type defects in aluminium alloys processed by equal channel angular pressing (ECAP) and accumulative roll bonding (ARB). ECAP at room temperature and cryogenic temperature was conducted to AA1050 and ARB with $200{ }^{\circ} \mathrm{C}$ preheating was conducted to AA1050 and AA6061 to produce laminated AA1050 sheets, AA6061 sheets and AA1050/AA6061 composites. High fraction of vacancy-type defects were detected in all the deformed samples. Vacancies associated with dislocations and bulk mono-vacancies have been identified in RT-ECAP deformed samples. Three types of vacancy-type defects, vacancies associated with dislocations, bulk mono-vacancies and bulk di-vacancies, have been identified in the CT-ECAP processed samples. The ARB process is more efficient in grain refinement and strengthening. However, the accumulation of vacancy-type defects in ARB deformation seems less efficient. Vacancies associated with dislocations are the major vacancy-type defects for ARB processed AA1050 sheets but there exist some bulk mono-vacancies. However, most of the vacancy-type defects in the ARB processed AA6061 are vacancies associated with dislocations. A very small fraction of bulk mono-vacancies can be extracted but it is so small that it can be neglected. The lifetimes of ARB processed AA1050/AA6061 composites are generally in between the values of AA1050 sheets and AA6061 sheets. Voids were not detected in neither of the samples.
\end{abstract}

KEYWORDS:

\section{INTRODUCTION}

The average grain size of materials generally plays a significant role on the mechanical properties of all crystalline materials. According to the well-known Hall-Petch equation, the strength increases with a reduction in the grain size. ${ }^{1}$ Thus fabricating materials with a grain size in the nano-range (less than $100 \mathrm{~nm}$ ) or ultrafine range (between $100 \mathrm{~nm}$ and $1 \mu \mathrm{m}$ ) is an attractive approach to increase the strength of materials. ${ }^{2}$

Severe plastic deformation (SPD) is used to process ultrafine grained (UFG) materials from coarse grained metals and alloys. ${ }^{3}$ The process is capable of generating large

\footnotetext{
*Author to whom correspondence should be addressed.

Email: chenglu@uow.edu.au

Received: 5 October 2012

Accepted: 21 May 2013
}

plastic strains that significantly refines the microstructure without altering the external dimensions of the specimens. Many different SPD processing techniques have been developed, including equal channel angular pressing (ECAP) ${ }^{4}$ high pressure torsion (HPT) ${ }^{5}$ multi-directional forging, ${ }^{6}$ accumulative roll bonding (ARB), ${ }^{7}$ and many others. All of these procedures are capable of introducing large plastic strains and obtaining significant microstructural refinement in bulk crystalline materials. Of these various procedures, ECAP and ARB are the most commonly used techniques.

Aluminium and its alloys have great potential in automotive and aerospace industry due to their light-weight nature, good formability, good corrosion resistance and low cost. ${ }^{8-10}$ However, the application is limited mostly due to their low strength compared with other metallic 
materials. Therefore, using SPD techniques to improve the strength of aluminium and its alloys should expand their usage in these industries.

The defects in aluminium generated by SPD include grain boundaries, dislocations, vacancies, etc. The fraction of the grain boundaries in the UFG materials is large compared to their coarse grained counterparts. Detailed knowledge of these defects can lead to a better understanding of the properties of SPD processed materials. Positron annihilation lifetime spectroscopy (PALS) is a non-destructive technique to study defects in solids, especially open-volume defects such as vacancies, vacancy clusters and dislocations. ${ }^{11}$ Because the positron lifetime is sensitive to the electron density at the trapping site, different lifetimes that are characteristic for different types of defects can be recorded. PALS is well-suited to study the defect structure and evolution during deformation, and has been used to study the defects in solids for over 30 years. Recently, PALS was also used to investigate the defects in UFG metals processed by SPD, and it is always combined with transmission electron microscopy (TEM), X-ray diffraction (XRD) and other techniques to investigate the defect evolution during SPD. ${ }^{12-18}$

In the present work, ECAP and ARB were used to process aluminium alloys. TEM, tensile test and PALS were used to investigate the microstructure, mechanical properties and vacancy-type defects of the materials after deformation.

\section{EXPERIMENTAL DETAILS}

The material used in ECAP was commercially pure aluminium AA1050. Billets were cast and heat treated at $456{ }^{\circ} \mathrm{C}$ for $1 \mathrm{~h}$ and then air cooled to room temperature. The ECAP die (as shown in Fig. 1) has a cross-section of $20 \times 20 \mathrm{~mm}^{2}$, an intersection angle of $90^{\circ}$ and an outer arc of curvature of $20^{\circ}$, which provides an equivalent strain of approximately 1 per ECAP pass. The billets were pressed up to 8 passes to achieve an equivalent strain of $\sim 8$ via route $B_{C}$ at a speed of $7 \mathrm{~mm} / \mathrm{s}$, with one group pressed at

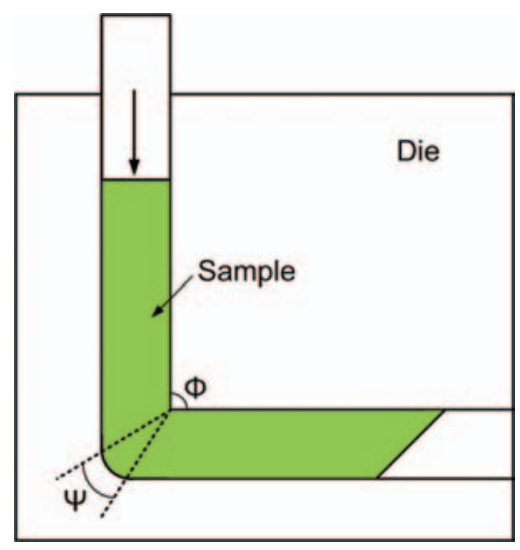

Fig. 1. Schematic illustration of the ECAP process room temperature (RT-ECAP) and the other group cooled with liquid nitrogen between each pass (CT-ECAP).

The materials used in ARB are commercial aluminium alloy AA1050 and AA6061 with an initial thickness of $1.5 \mathrm{~mm}$. The AA1050 was heat treated at $450{ }^{\circ} \mathrm{C}$ for $1 \mathrm{~h}$ and the AA6061 was heat treated at $500{ }^{\circ} \mathrm{C}$ for 2 h. Before ARB, strips with a dimension of $400 \times 50 \times$ $1.5 \mathrm{~mm}^{3}$ (length $\times$ width $\times$ thickness) were cut from the original sheets, with the longitudinal direction parallel to the original rolling direction. The ARB processing was categorised into three groups, one group using AA1050 as primary materials, one using AA6061 and another group using a combination of AA1050 and AA6061 as staring materials. Three types of sheets: AA1050, AA6061 and AA1050/AA6061 were produced. The ARB process is schematically shown in Figure 2. The roll diameter was $125 \mathrm{~mm}$ and the rolling speed was $196 \mathrm{~mm} / \mathrm{s}$. Prior to each rolling cycle, the rolls were cleaned by acetone. One side of the sample was cleaned with acetone and wire-brushed. Two pieces of the samples were then stacked and welded together at one end, pre-heated in a furnace at $200{ }^{\circ} \mathrm{C}$ for $3 \mathrm{~min}$, and then rolled with a nominal reduction of $\sim 50 \%$ without lubricant, which gives an accumulated Von Mises equivalent strain of $\sim 0.8$. This pre-heating temperature was chosen to achieve good hardening and bonding simultaneously. ${ }^{19}$ The rolled samples were cut into two halves and stacked together again to perform the next cycle. The above procedure was carried out for five cycles to achieve an accumulative strain of $\sim 4$.

Tensile tests were conducted to investigate the mechanical properties of the severe plastically deformed samples. TEM micrographs were taken on the ED-ND plane of ECAP processed samples and the RD-ND plane of the ARB processed samples. Thin foils were sliced from the plane perpendicular to the pressing direction, mechanically ground to less than $200 \mu \mathrm{m}$ thick, and then twin-jet electron polished with the Struers Tenupol polishing machine in a solution of $20 \%$ nitric acid and $80 \%$ methanol at $-20{ }^{\circ} \mathrm{C}$.

PALS measurements were carried out on the 1,4 and 8-pass ECAP processed samples and 1, 3 and 5-cycle ARB processed samples. Two specimens with the same dimension of $20 \times 20 \times 2 \mathrm{~mm}^{3}(\mathrm{ND} \times \mathrm{TD} \times \mathrm{ED})$ were cut from the ECAP and ARB processed samples. The positron source $\sim 30 \mu \mathrm{Ci}$ of ${ }^{22} \mathrm{NaCl}$ was sealed in a $7 \mu \mathrm{m}$ thick Kapton foil and sandwiched between the two identical samples. The measured lifetime spectra were analysed using the MELT 4.0 program.

\section{RESULTS AND DISCUSSION}

\subsection{Microstructure}

Figure 3 shows TEM microstructures of the ECAP and ARB processed materials to the most deformed state. The microstructure of the 8-pass RT-ECAP processed AA1050 comprises equiaxed grains with most of the grain interiors 


\section{Original sheets Surface treatment Roll bonding $\quad$ Cutting}

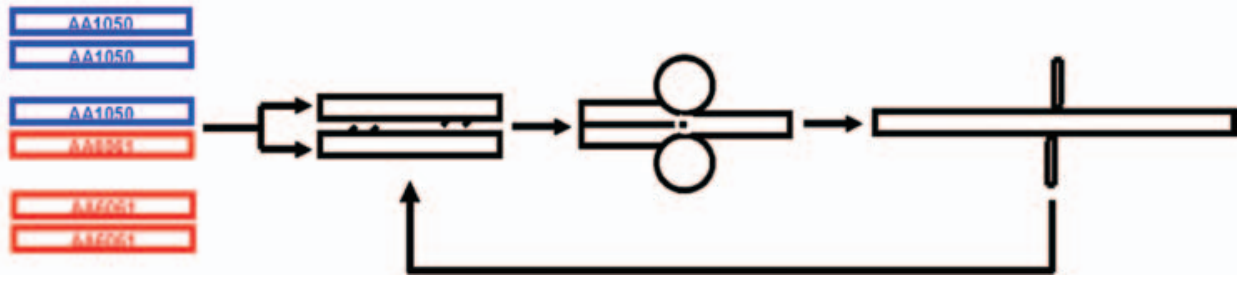

Fig. 2. Schematic illustration of the ARB process.

free of dislocations, as can be seen in Figure 3(a). The 8-pass CT-ECAP processed AA1050, on the other hand, contains a lot of grains with high densities of dislocations inside (Fig. 3(b)).

Figures 3(c) and (d) show the microstructures of the 5-cycle ARB processed AA1050 and AA6061, respectively. It can be seen that the microstructures of the AA6061 and AA1050 layers are obviously different after the same cycle ARB. The grains of the AA6061 layers are more elongated with a smaller band width and a larger aspect ratio as compared to the AA1050 layers. The 5-cycle ARB processed AA6061 shows elongated grains with HAGBs and most of the grain interiors are free of dislocations. The average band width has been refined to approximately $139 \mathrm{~nm}$. The microstructures of the AA1050 and AA6061 layers in the AA1050/AA6061 composites were compared before and found that they are similar to that of their corresponding monotonic sheets. ${ }^{20}$

The average grain size of both the 8-pass RT-ECAP and CT-ECAP processed AA1050 is around $500 \mathrm{~nm}$, while the average grain size of the 5-cycle ARB processed AA1050 is about $300 \mathrm{~nm}$, which is significantly smaller than the ECAP processed AA1050, indicating that the grains are more refined during the ARB process. (Note that the grain size of the ARB processed samples is averaged from the widths of the slightly elongated grains.)

Micron-sized precipitates can also be observed in the AA6061 layers after ARB, which make it possible to distinguish the AA6061 layers from the AA1050 layers in optical micrographs. Figure 4(a) shows the optical micrograph around the centre interface of the ARB processed AA1050/AA6061 composite after polishing to a Struers
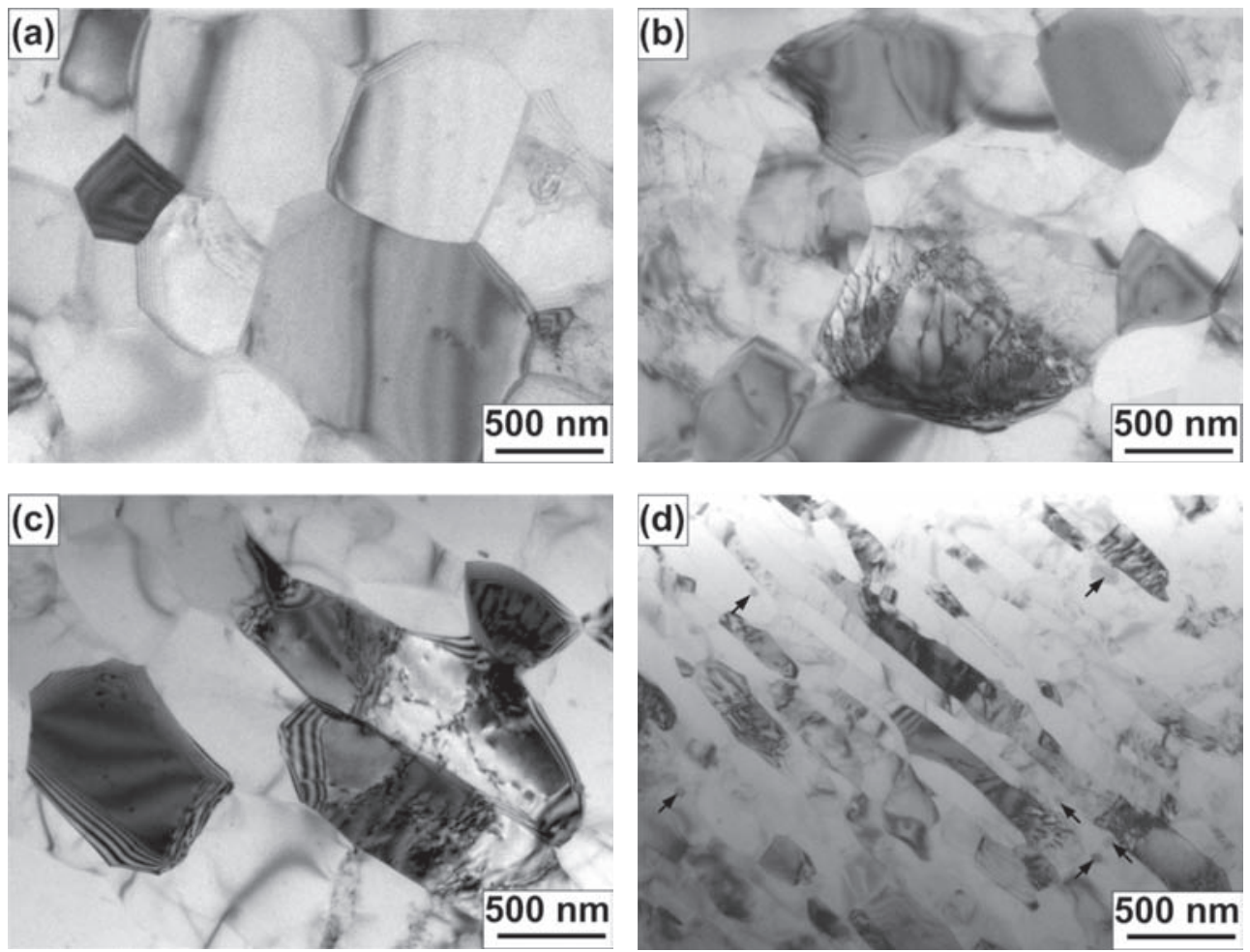

Fig. 3. TEM microstructures of (a) 8-pass RT-ECAP processed AA1050, (b) 8-pass CT-ECAP processed AA1050, (c) 5-cycle ARB processed AA1050 sheets and (d) 5-cycle ARB processed AA6061 sheets. 

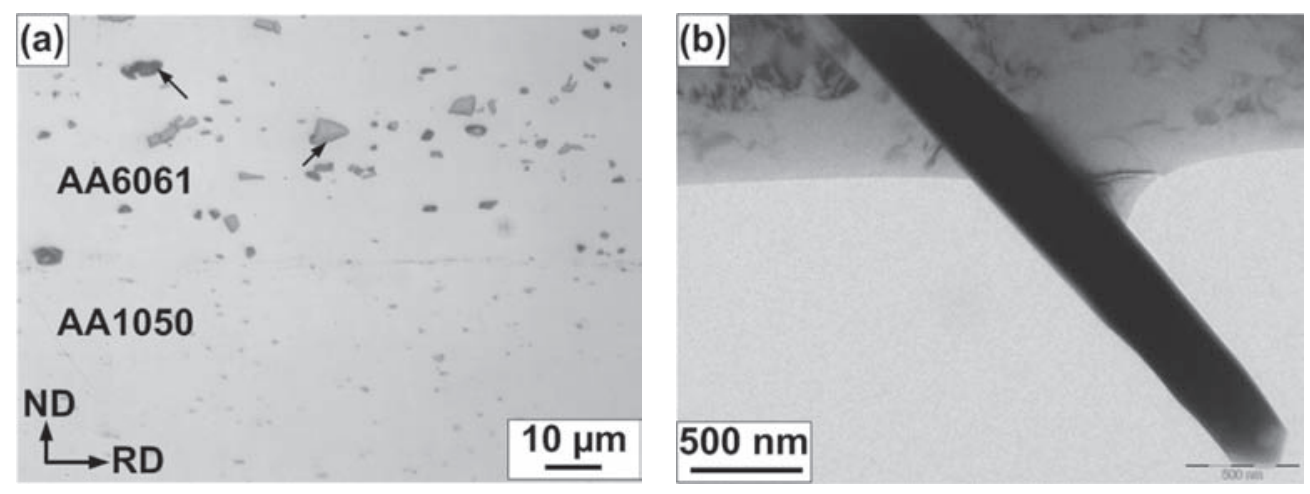

Fig. 4. Micron-sized precipitates in the AA6061 layers, (a) optical micrograph and (b) TEM micrograph.

OPS finish. The two layers can be identified by the dense micron-sized precipitates in the AA6061 layers. Two types of precipitates can be identified from the figure. One type is gray in colour and is reported as $\mathrm{Mg}_{2} \mathrm{Si}$, and the other is $\mathrm{Fe}$ enriched precipitate and is black in colour. ${ }^{8}$ Both precipitates are in the micron size range and the size does not change much through the ARB process. Figure 4(b) shows a TEM graph of a typical micron-sized precipitate. As revealed by Energy dispersive X-ray spectroscopy (EDS), the long rod shaped precipitate is $\mathrm{Si}$ and $\mathrm{O}$ enriched, with smaller amounts of $\mathrm{Al}, \mathrm{Mg}, \mathrm{Fe}$ and $\mathrm{Co}$.

Besides the micron-sized precipitates, nano-sized precipitates were also observed in the AA6061 layers (indicated by arrows in Fig. 3(d)). The fine precipitates have a regular facetted shape and are about 50-150 nm in size. The coarse and fine precipitates in the AA6061 layer might behave as obstacles to dislocation movements and this may be one of the reasons for the more refined microstructure in this layer.

The structure of a nano-sized precipitate was analysed by selected area electron diffraction (SAD) and highresolution TEM imaging and the results are shown in Figure 5. It can be seen in Figure 5(a) that the precipitate is about $50 \mathrm{~nm}$ in size and has a regular shape. Preliminary results obtained from several different SAD zone axis patterns indicate that the precipitate has a body-centred cubic (BCC) crystal structure and a lattice parameter of $1.284 \mathrm{~nm}$. Figure 5(b) shows a precipitate SAD pattern which can be indexed as $\left[\begin{array}{lll}0 & 0 & 1\end{array}\right]$ zone axis. Coherent relationship of the precipitate with the $\mathrm{Al}$ matrix can be described as $\left\langle\begin{array}{llll}0 & 0 & 1\end{array}\right\rangle_{\text {precipitate }} / /\left\langle\begin{array}{lll}0 & 1 & 1\end{array}\right\rangle_{\mathrm{Al}}$ and $\left\{\begin{array}{lll}2 & 0 & 0\end{array}\right\}_{\text {precipitate }} / /\left\{\begin{array}{lll}2 & 0 & 0\end{array}\right\}_{\mathrm{Al}}$. Note that the $\{200\}$ spacing of the precipitate is three times that of the Al matrix, which indicates that the lattice constant of the precipitate is about three times that of aluminium. High-resolution TEM images of the precipitate are shown in Figures 5(c) and (d) and their corresponding SAD patterns are shown in Figures 5(e) and (f). Figure 5(c) is observed along the $\left[\begin{array}{lll}0 & 0 & 1\end{array}\right]$ zone axis of the BCC structured precipitate and Figure 5(d) along the [ [ $\left.\begin{array}{lll}1 & 1 & 1\end{array}\right]$ zone axis. The spacing of the $\left\{\begin{array}{lll}1 & 1 & 0\end{array}\right\}$ planes is measured and marked in both graphs.

\subsection{Tensile Strength}

The tensile properties of the ECAP and ARB processed sheets are shown in Figure 6. The error bars in Figure 6 are smaller than the symbols. The tensile strength increases with the accumulated strain from ECAP and ARB deformation for all the samples and the values after 8-pass ECAP and 5-cycle ARB are more than two times greater than the initial values.

Figure 6 shows that the tensile strengths of the ARB processed samples are significantly higher than the ECAP processed ones. As has been mentioned earlier, the microstructures of the ARB processed samples are more refined, which is in correspondence with the higher strengths. It can be concluded that ARB deformation is more efficient in microstructure refinement and strengthening. Note that the ARB deformation in this work was conducted at an elevated temperature, which may accelerate the dynamic recovery during deformation and restrict the microstructure refinement and strengthening. The efficiency of ARB deformation would be more obvious if the $\mathrm{ARB}$ process was conducted at room temperature or lower. Cherukuri et al. conducted ARB and ECAP deformation on AA6061 up to the same accumulative strain at the same temperature and found that ARB processed samples had higher hardness and strength, ${ }^{21}$ which is consistent with the results of the present work.

It can also be seen in Figure 6 that the tensile strength of the AA6061 sheets is always the highest for the three kinds of ARB processed sheets, and that of the AA1050 sheets are the lowest, while the tensile strength of the AA1050/AA6061 composites is located in between the two monotonic material sheets. Detailed discussion was given in Ref. [20].

\subsection{Positron Lifetime}

The PALS results of the ECAP and ARB processed samples are shown in Figures 7-9. Two positron lifetime components were obtained for all the ECAP and ARB processed samples: a short lifetime $\tau_{1}$ and a long lifetime $\tau_{2}$. All of the $\tau_{1}$ values are smaller than the bulk Al lifetime obtained from a fully annealed aluminium sample 

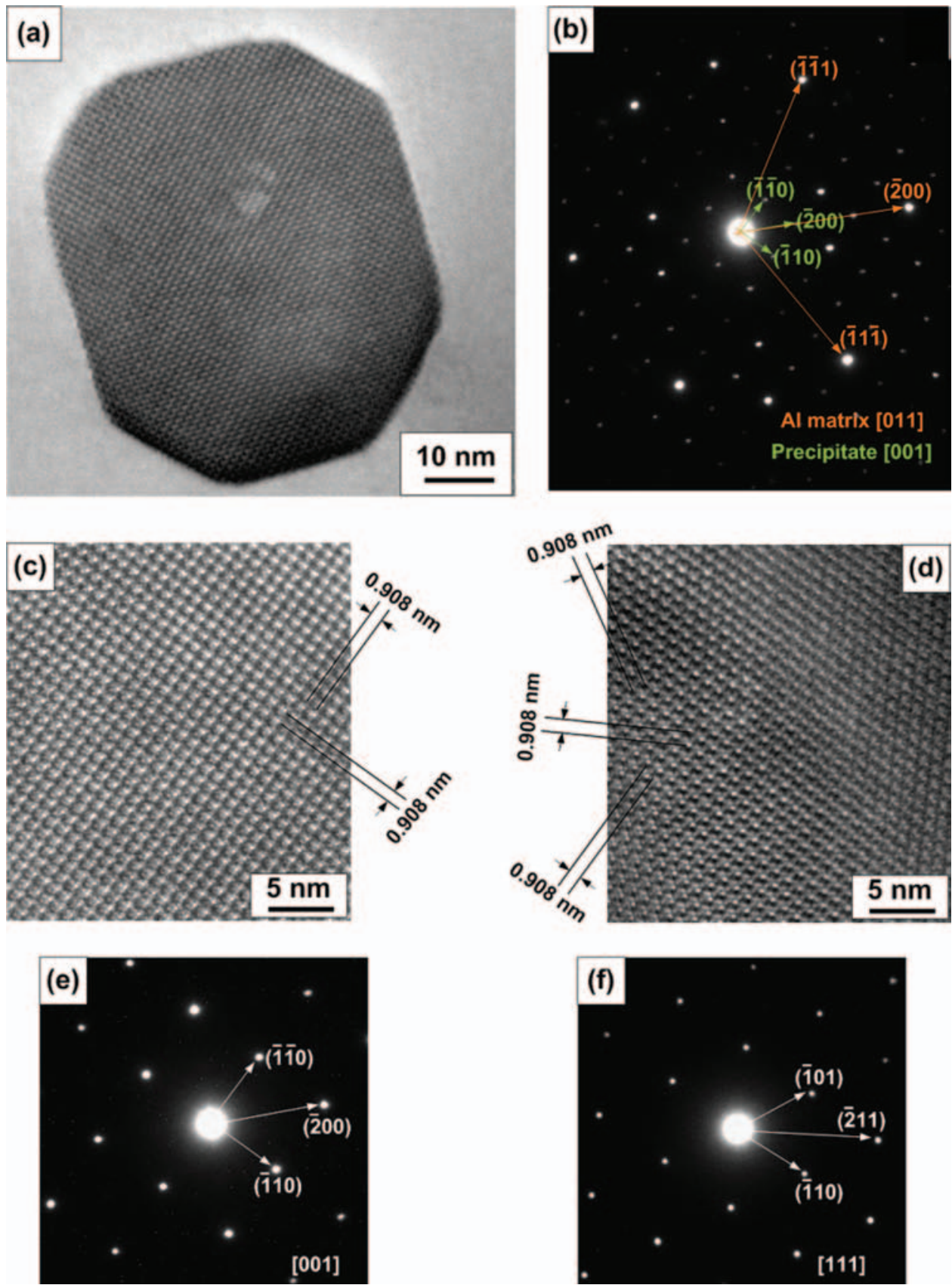

Fig. 5. TEM characterisation of a nano-sized precipitate in the AA6061 layer of the 5-cycle ARB processed AA1050/AA6061 composite, (a) overall image (b) SAD pattern showing the coherency relationship with the aluminium matrix, (c) HRTEM image viewed along the $\left[\begin{array}{llll}0 & 0 & 1\end{array}\right]$ zone axis, (d) HRTEM image viewed along the [lll 11 l] zone axis, (e) and (f) the corresponding SAD patterns of (c) and (d), respectively.

( $\sim 162 \mathrm{ps})$, while the $\tau_{2}$ values vary between $210 \mathrm{ps}$ and 250 ps.

The ECAP processed samples have longer positron lifetime values and smaller long lifetime fractions compared to the ARB processed samples. The CT-ECAP processed samples have longer lifetime values than the RT-ECAP samples, the reason of which has been discussed in detail in Ref. [22].

The effect of different processing techniques can be concluded by comparing the results of AA1050 after
RT-ECAP, CT-ECAP and ARB to the same strain, in the current case, being 4-pass ECAP and 5-cycle ARB, the accumulated strain of which are all $\sim 4$. The long positron lifetime $\tau_{2}$ of the 5-cycle ARB processed AA1050 is $223.6 \mathrm{ps}$, which is much smaller than those for the 4-pass ECAP processed AA1050, as can be seen in Figure 8. The lifetimes of 4-pass RT-ECAP processed and 5-cycle ARB processed AA1050 are between the values of vacancies associated with dislocations and mono-vacancies in the bulk, with the former closer to mono-vacancies and 


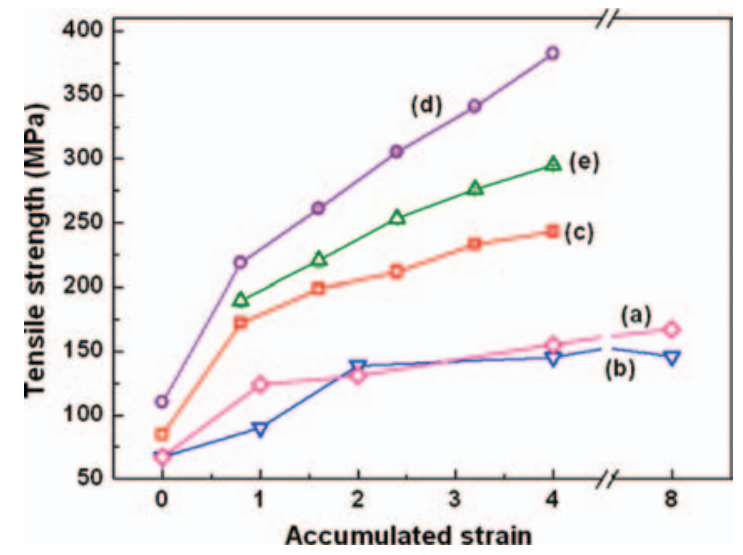

Fig. 6. Tensile strength values of (a) CT-ECAP and (b) RT-ECAP processed AA1050, ARB processed (c) AA1050 sheets, (d) AA6061 sheets, (e) AA1050/AA6061 composites. (0 ARB cycle corresponding to hardness of annealed materials, the same for the following figures).

the latter closer to vacancies associated with dislocations, while the long lifetime of 4-pass CT-ECAP processed AA1050 is larger than the value of mono-vacancies in the bulk. The intensities of the long lifetime $I_{2}$ for all three samples are higher than $80 \%$. It can be found from the lifetime values that vacancies associated with dislocations are the dominant vacancy-type defects in the 5-cycle ARB processed AA1050, whereas bulk mono-vacancies are dominant in the 4-pass RT-and CT-ECAP processed AA1050. The fraction of the positrons annihilated in the bulk of the 5-cycle ARB processed sample is smaller than the ECAP processed samples, indicating a large fraction of defects in the ARB processed sample. The defect fraction is difficult to be detected by other methods like TEM. TEM micrographs show high dislocation densities of all the samples but it is not possible to determine which sample has the higher fraction. Combination of TEM with PALS is an effective way to evaluate the defects in the samples.

The ARB process is more efficient in grain refinement and strengthening, as stated above. However, the

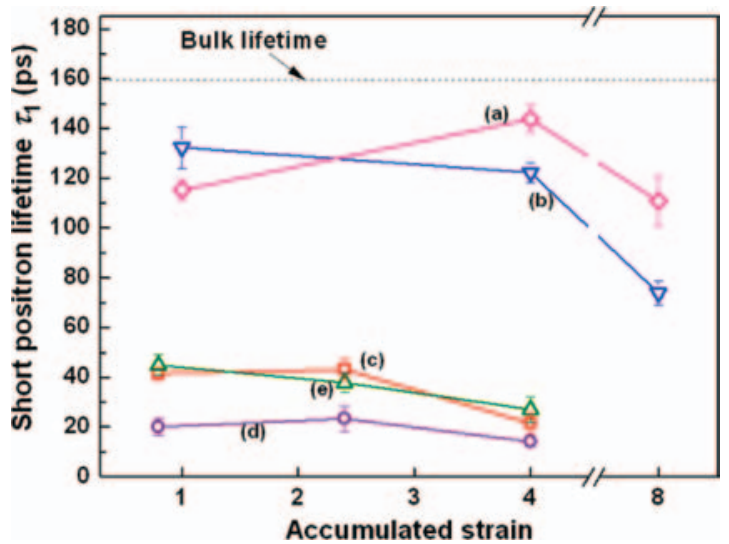

Fig. 7. Short positron lifetime $\tau_{1}$, (a)--(e) represent the same samples as indicated in Figure 6.

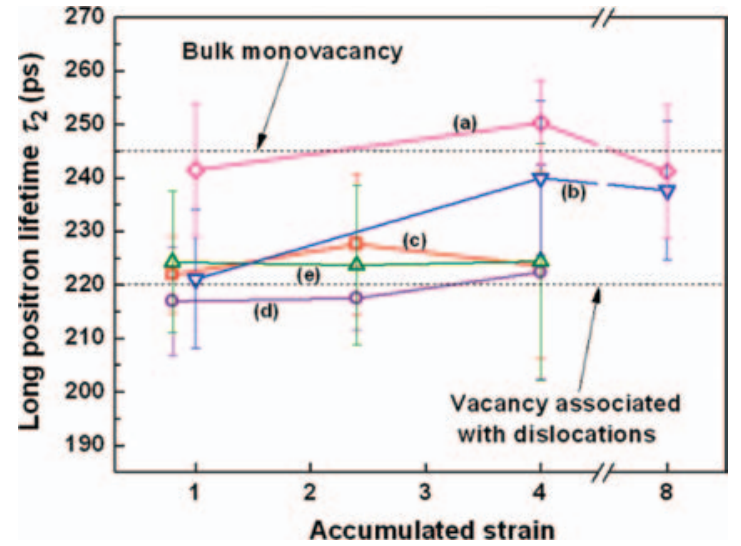

Fig. 8. Long positron lifetime $\tau_{2}$, (a)-(e) represent the same samples as indicated in Figure 6.

accumulation of vacancy-type defects in ARB deformation seems less efficient, as indicated by the smaller long lifetime in Figure 8. The major reason might be because of the elevated deformation temperature for ARB. The lifetime values obtained in this work are also smaller than the lifetimes of pure aluminium processed by ARB at room temperature. ${ }^{23}$ Although the stress state in the SPD processed sample is able to restrict the mobility of vacancies, the intermittent heating temperature used in this work is high enough for thermal activation of dislocations, the movement of which would result in vacancy annihilation to the dislocations or other defects like the grain boundaries. Since the concentration of mono-vacancies is smaller for the 5-cycle ARB processed AA1050, the number of vacancy pinning centres is therefore less than the 4-pass RT- and CT-ECAP processed samples. The higher hardness and strength of the 5-cycle ARB processed AA1050 is most probably resulted from grain refinement hardening due to the smaller grain size compared with the ECAP processed samples.

To date, positron lifetime examination on ARB processed aluminium has rarely been reported. Pure

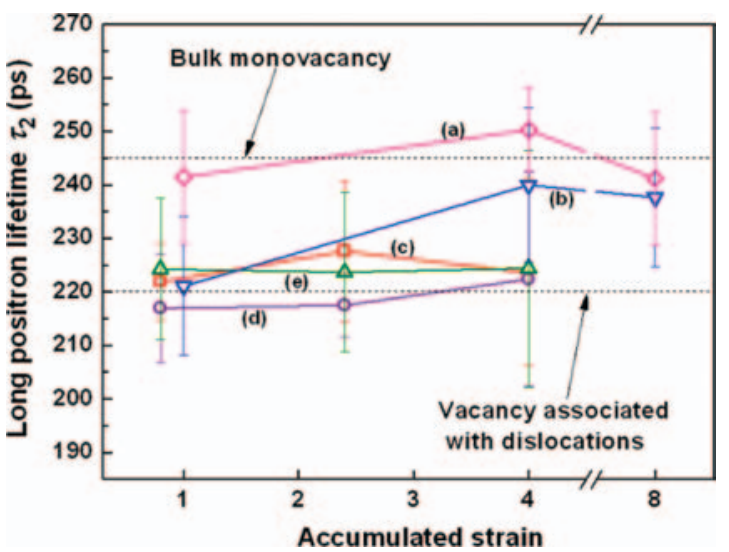

Fig. 9. Intensity of long lifetime $I_{2}$, (a)-(e) represent the same samples as indicated in Figure 6 
aluminium $^{23}$ and $\mathrm{AA}^{2} 8006^{24}$ are the two references on the ARB processed aluminium investigated by PALS and both work did not provide a detailed discussion. The types of defects in the ARB processed samples are supposed to be more than that in the ECAP processed samples because the interfaces between different layers in ARB processed sheets are also defects in the samples. However, this type of defects is not always able to be detected by PALS. Normally, voids are believed to exist along the interfaces. But the lack of any long lifetimes corresponding to voids in the PALS results suggests that there are no voids in the samples. The reason might be because of the good bonding quality of the sheets so that voids do not appear until after tensile deformation.

Vacancies associated with dislocations are the major vacancy-type defects but some bulk mono-vacancies for the ARB processed AA1050 sheets still exist. However, most of the vacancy-type defects in the ARB processed AA6061 sheets are vacancies associated with dislocations. A very small fraction of bulk mono-vacancies can be extracted but it is so small that it can be neglected. The major microstructure difference of the ARB processed AA6061 and AA1050 is the smaller grain size and the dense precipitates in the AA6061. The small grain size offers large fractions of grain boundaries which are supposed to be able to increase the possibility of positrons annihilating at vacancies associated with dislocations. However, the smaller $\tau_{2}$ values obtained are contradicted to this assumption. Therefore, the precipitates in the AA6061 sheets must play an important role in the positron annihilation.

Precipitates in aluminium alloys can be described by three types: coherent, semi-coherent and incoherent. ${ }^{25}$ All three types of precipitates can be detected with positron annihilation by combining lifetime measurements with Doppler broadening. ${ }^{25}$ Principally, coherent precipitates can act as shallow positron traps, but for incoherent precipitates, trapping occurs at misfit interfaces between the matrix and the interfaces, which is comparable to grain boundaries and gives a similar lifetime value. ${ }^{25,26}$ The positron lifetime related to the coherent precipitates in aluminium alloys is reported to be around 210 ps in Refs. [26, 27], and 220 ps in Ref. [28]. In Ref. [29], positron annihilation was conducted to solution treated and aged and HPT deformed AA2017. Long lifetime $\tau_{2}$ is determined to be $\sim 225 \mathrm{ps}$ for the solution treated and aged sample and $\sim 240$ ps for the HPT deformed sample. It was stated that the positrons are trapped in $\mathrm{Cu}$-vacancy complexes and $\theta^{\prime}-\mathrm{Al}$ interfaces for the solution treated and aged sample. It can be concluded that the positron lifetime for coherent precipitates is slightly smaller than the lifetime for incoherent precipitates and is similar to the vacancies associated with dislocations.

The nano-sized precipitates in AA6061 are coherent with the matrix (shown in Fig. 5) and can be considered as shallow positron traps. The micron-sized precipitates, on the other hand, provide dense dislocations along the precipitates-matrix interfaces which give lifetimes that are characteristic of vacancies associated with dislocations. The lifetimes from the two types of precipitates are close to the vacancies associated with dislocations, which make it difficult to be separated. Therefore, the $\tau_{2}$ values measured in the ARB processed AA6061 sheets are a combination of the characteristics of micronand nano-sized precipitates, vacancies associated with dislocations and bulk mono-vacancies. As the lifetimes of the precipitates are smaller or close to the vacancies associated with dislocations, the overall lifetimes of the ARB processed AA6061 sheets appear to be smaller than the sample without precipitates, such as ARB processed AA1050.

As the fractions of AA1050 and AA6061 are approximately equal to each other in the AA1050/AA6061 composites, the fraction of positrons annihilated in the two layers is supposed to be equal. The positron lifetime values may also apply to the rule of mixture. As a matter of fact, the $\tau_{2}$ values of the ARB processed AA1050/AA6061 composites are generally in between the values of AA1050 and AA6061 sheets, with a small variation for the 1-cycle ARB processed samples. This variation might be because of the measurement errors. The error bars of the lifetimes of the ARB processed samples are larger than that of the ECAP processed samples, as can be compared in Figures 7-9. The reason is because the types of defects in the ARB processed samples are more than the ECAP processed samples, especially the refined microstructure in the interfacial areas and the precipitates in the bulk. These defects result in lifetimes close but not equal to the vacancies associated with dislocations, which makes it difficult to resolve but increase the error bars.

\section{CONCLUSION}

In the present work, AA1050 was processed by ECAP at room temperature and cryogenic temperature, and ARB with $200{ }^{\circ} \mathrm{C}$ pre-heating was used to produce laminated AA1050 sheets, AA6061 sheets and AA1050/AA6061 composites. Microstructure, mechanical properties and vacancy-type defects evolution were investigated and the following can be concluded.

(1) The microstructures of all the initial materials were refined significantly after ECAP and ARB deformation. The ARB process is more efficient in grain refinement.

(2) The tensile strengths were strengthened up to more than two times of the initial values after ECAP and ARB deformation. The ARB process is more efficient in strengthening.

(3) High fraction of vacancy-type defects were detected in all the deformed samples. The ECAP processed AA1050 have longer long lifetime then the ARB processed AA1050 to the same accumulated strain, indicating the accumulation of vacancy-type defects in ARB deformation is less efficient. 
(4) ARB processed AA6061 sheets have shorter long lifetime than the AA1050 sheets, mostly due to the dense micron- and nano-sized precipitates in the AA6061 sheets. The lifetimes of ARB processed AA1050/AA6061 composites are generally in between the values of AA1050 sheets and AA6061 sheets.

\section{References and Notes}

1. N. J. Petch, J. Iron. Steel. I. 174, 25 (1953)

2. R. Valiev, Nat. Mater. 3, 511 (2004).

3. R. Z. Valiev, R. K. Islamgaliev, and I. V. Alexandrov, Prog. Mater. Sci. 45, 103 (2000).

4. V. M. Segal, Mater. Sci. Eng. A 197, 157 (1995).

5. M. Kai, Z. Horita, and T. G. Langdon, Mater. Sci. Eng. A 488, 117 (2008).

6. Y. Nakao and H. Miura, Mater. Sci. Eng. A 528, 1310 (2011).

7. Y. Saito, H. Utsunomiya, N. Tsuji, and T. Sakai, Acta Mater. 47, 579 (1999).

8. J. E. Hatch (ed.), Aluminum-Properties and Physical Metallurgy, American Society for Metals (1984).

9. L. P. Troeger and E. A. Starke, Jr, Mater. Sci. Eng. A 277, 102 (2000).

10. S. H. Lee, Y. Saito, T. Sakai, and H. Utsunomiya, Mater. Sci. Eng. A 325, 228 (2002).

11. R. Krause-Rehberg and H. Leipner, Positron Annihilation in Semiconductors, Springer-Verlag, Berlin (1999).

12. W. Lechner, W. Puff, G. Wilde, and R. Würschum, Scripta Mater. 62, 439 (2009).

13. J. Č́ižek, I. Procházka, B. Smola, I. Stulíková, R. Kužel, Z. Matìj, V. Cherkaska, R. K. Islamgaliev, and O. Kulyasova, Mater. Sci. Eng. A 462, 121 (2007).
14. R. Ferragut, P. V. Liddicoat, X.-Z. Liao, Y.-H. Zhao, E. J. Lavernia, R. Z. Valiev, A. Dupasquier, and S. P. Ringer, J. Alloy. Compd. 495, 391 (2010).

15. J. Čížek, M. Janeček, O. Srba, R. Kužel, Z. Barnovská, I. Procházka, and S. Dobatkin, Acta Mater. 59, 2322 (2011).

16. J. Čížek, I. Procházka, M. Cieslar, R. Kužel, J. Kuriplach, F. Chmelík, I. Stulíková, F. Bečvár̆, O. Melikhova, and R. K. Islamgaliev, Phys. Rev. B 65, 094106 (2002).

17. R. Krause-Rehberg, V. Bondarenko, E. Thiele, R. Klemm, and N. Schell, Nucl. Instrum. Meth. B 240, 719 (2005).

18. R. Kuzel, Z. Matej, V. Cherkaska, J. Pesicka, J. Č́̌žek, I. Procházka, and R. K. Islamgaliev, J. Alloy. Compd. 378, 242 (2004).

19. I. Topic, H. W. Höppel, and M. Göken, Inter. J. Mater. Res. 98, 320 (2007).

20. L. H. Su, C. Lu, A. K. Tieu, G. Y. Deng, and X. D. Sun, Mater. Sci. Eng. A 651, 514 (2013).

21. B. Cherukuri, T. S. Nedkova, and R. Srinivasan, Mater. Sci. Eng. A 410-411, 394 (2005)

22. L. H. Su, C. Lu, L. Z. He, L. C. Zhang, P. Guagliardo, A. K. Tieu, S. N. Samarin, J. F. Williams, and H. J. Li, Acta Mater. 60, 4218 (2012).

23. M. Slamova, P. Homola, P. Slama, J. Cizek, I. Prochazka, and M. Cieslar, Mater. Sci. Forum. 503-504, 711 (2006).

24. P. Homola, M. Slamova, M. Karlik, J. Cizek, and I. Prochazka, Mater. Sci. Forum. 503-504, 281 (2006).

25. T. E. M. Staab, E. Zschech, and R. Krause-Rehberg, J. Mater. Sci. 35, 4667 (2000).

26. A. Dupasquier, G. Kögel, and A. Somoza, Acta Mater. 52, 4707 (2004)

27. T. E. M. Staab, R. Krause-Rehberg, U. Hornauer, and E. Zschech, J. Mater. Sci. 41, 1059 (2006).

28. W. Egger, G. Kögel, P. Sperr, W. Triftshäuser, J. Bär, S. Röling, and H. J. Gudladt, Mater. Sci. Eng. A 387-389, 317 (2004).

29. W. Lechner, W. Puff, R. Wuerschum, G. Wilde, M. J. Zehetbauer, and R. Pippan, Phys. Status. Solidi. C 6, 2313 (2009). 